\title{
Ankylosing spondylitis: a chronic inflammatory disease with iron overload in granulocytes and platelets
}

\author{
NILS FELTELIUS, ${ }^{1}$ ULF LINDH, ${ }^{3}$ PER VENGE, ${ }^{2}$ AND \\ ROGER HÄLLGREN ${ }^{1}$
}

From the Departments of ${ }^{1}$ Internal Medicine and ${ }^{2}$ Clinical Chemistry, University Hospital, Uppsala, Sweden; and the ${ }^{3}$ Gustaf Werner Institute, Department of Physical Biology, Uppsala, Sweden

SUMMARY The cellular stores of iron in granulocytes and platelets isolated from 29 patients with ankylosing spondylitis were measured by the nuclear microprobe technique. The mean iron content in polymorphonuclear cells (PMNs) was 32 (SD 3) $\mu \mathrm{g} / \mathrm{g}$ dry weight and in platelets 11 $(2 \cdot 6) \mu \mathrm{g} / \mathrm{g}$ dry weight. Corresponding values for age and sex matched healthy controls were $5 \cdot 2$ (1.9) and $4.6(0.8) \mu \mathrm{g} / \mathrm{g}(\mathrm{p}<0.001)$. Significant correlations were found in the patient group between $(P M N)$ iron and the circulating levels of transferrin, total iron, and lactoferrin $(p<0 \cdot 05)$. PMN iron was not related to serum ferritin. Platelet iron correlated with transferrin $(\mathrm{p}<0 \cdot 01)$ but not with the other iron binding proteins. Significant relationships were also found between the PMN iron stores and the inflammatory activity defined by erythrocyte sedimentation rate (ESR) and the immunoglobulins $A$ and $G$. These data further illustrate the altered iron kinetics in chronic inflammatory disease and record the fact that the redistribution of iron associated with the inflammatory process also includes granulocytes and platelets.

Key words: cellular iron stores, nuclear microprobe, iron binding proteins, iron kinetics, inflammatory activity.

The anaemia and hypoferraemia of inflammatory disease have been widely discussed. Both beneficial and noxious effects in the inflammatory processes have been attributed to iron. Studies of iron kinetics in inflammatory disease have shown abnormal accumulation of iron in RE cells, possibly due to an increased uptake and a partly blocked release. ${ }^{1}$ In rheumatoid arthritis a relation has been proposed between the presence of iron in the joint and the development of joint damage. ${ }^{2}$ Intra-articular deposits of iron have been suggested to have an 'antigenic' role by attracting inflammatory cells, with receptors for iron binding proteins, to the rheumatoid synovium, thus initiating a vicious inflammatory circle. ${ }^{3}$

Although most probably an important element in inflammatory processes, the true role of iron at a

\section{Accepted for publication 9 April 1986.}

Correspondence to Dr Nils Feltelius. Section of Rheumatology, Department of Internal Medicine, University Hospital, S-751 85 Uppsala. Sweden. cellular level has not been finally decided. To elucidate further the importance of iron in rheumatic disease a group of patients with ankylosing spondylitis was investigated. A new technique was used to estimate the intracellular stores of iron in granulocytes and platelets. The results were correlated with the degree of inflammatory activity and with the level of iron binding proteins.

\section{Patients and methods}

\section{PATIENTS}

Twenty nine consecutively recruited outpatients with definite AS according to American Rheumatism Association criteria (New York) were investigated. They all had the tissue antigen HLA-B27. The patients were admitted to hospital for two days to standardise the blood sampling procedure. Age, sex, and duration of the disease are presented in Table 1. Laboratory data reflecting the degree of inflammatory activity and serum levels of iron, 
Table 1 Clinical and laboratory data in patients with ankylosing spondylitis*

\begin{tabular}{lcc}
\hline & Mean $(S D)$ & Range \\
\hline Age (years) & $43(9)$ & $22-55$ \\
Disease duration (years) & $11(7)$ & $1-30$ \\
Hb $(113-166) \dagger(g / 1)$ & $141(18)$ & $90-177$ \\
Serum Fe $(11-35)(\mu \mathrm{mol} /)$ & $19(8)$ & $6 \cdot 9-40$ \\
Transferrin $(45-72)(\mu \mathrm{mol} / 1)$ & $60(9)$ & $32-70$ \\
Ferritin $(10-240)(\mu \mathrm{g} / \mathrm{l})$ & $70(76)$ & $6 \cdot 3-307$ \\
Lactoferrin $(19-300)(\mu \mathrm{g} / \mathrm{l})$ & $281(76)$ & $144-454$ \\
ESR $(<15)(\mathrm{mm} / 1 \mathrm{st} \mathrm{h})$ & $27(26)$ & $3-111$ \\
Haptoglobin $(0 \cdot 3-2 \cdot 0)(\mathrm{g} / 1)$ & $3 \cdot 2(1 \cdot 1)$ & $1 \cdot 6-6 \cdot 1$ \\
IgG $(7 \cdot 0-18 \cdot 0)(\mathrm{g} / \mathrm{l})$ & $13 \cdot 5(3 \cdot 2)$ & $6 \cdot 2-21 \cdot 5$ \\
IgA $(0 \cdot 8-4 \cdot 0)(\mathrm{g} / \mathrm{l})$ & $3 \cdot 2(1 \cdot 2)$ & $0 \cdot 9-6 \cdot 2$ \\
\hline
\end{tabular}

${ }^{*} \operatorname{Sex} \sigma^{\prime \prime} / Q=24 / 5$.

†Reference values within parentheses.

transferrin, and ferritin are given in the same table. The patients that were treated with non-steroidal anti-inflammatory drugs had these withdrawn two to three days before blood sampling. None of the patients was treated with steroids. Twenty eight age and sex matched healthy individuals served as a control group. The study was performed with informed consent, according to the Declaration of Helsinki.

CELLUAR MASS FRACTION OF IRON

Venous blood $(10 \mathrm{ml})$ was drawn into Venoject tubes (Terumo, Tokyo, Japan) with $0.1 \mathrm{mg} 0.38$ $\mathbf{M K}_{3}$ ethylenediaminetetra-acetic acid (EDTA) as anticoagulant. Granulocytes and platelets were immediately isolated from the blood samples as previously described. ${ }^{4}$ After washing in sterile phosphate buffered saline pH 7.3 (SBL, Stockholm, Sweden) the different cell types were resuspended in $1 \mathrm{ml} \mathrm{0.32} \mathrm{M}$ iron free sucrose (Analar, BDH, London, England). Then $0.5 \mu \mathrm{l}$ aliquots (equivalent to approximately $0.5 \times 10^{4}$ granulocytes and $0.5 \times 10^{6}$ platelets respectively) were put onto clean Formvar films (Formvar $1595 \mathrm{E}$; Merck, Darmstadt, W Germany). After freezing to $-80^{\circ} \mathrm{C}$ the cells were freeze dried. During the period between preparation and analysis the cells were stored in desiccators over silica gel in darkness in a cooler. From the blood cell preparations 20 cells of each type were selected under the light microscope before microprobe analysis in the Studsvik nuclear microprobe. A technical account of the analytical instrument has been published elsewhere. ${ }^{5}$ The selected cells were irradiated with a $5 \mu \mathrm{m}$ beam of $2.5 \mathrm{MeV}$ protons from the Van de Graaff accelerator of the National Science Research Laboratory at Studsvik, Sweden. The induced spectra of characteristic $x$ rays were collected by a multichannel analyser for $300-800$ seconds and stored on tape for later treatment. Handling of the registered data was exercised in the way outlined by Lindh. ${ }^{6}$ The conversion of $x$ ray counts to relative amounts relies on the fact that the bremsstrahlung is proportional to the cellular mass under the probe. ${ }^{7}$ The merits of this technique as compared with backscattering and gammaray monitoring were evaluated for use in the Studsvik nuclear microprobe. ${ }^{5}$ The cellular concentrations of iron represent median values and are expressed in $\mu \mathrm{g} / \mathrm{g}$ dry weight.

The serum concentrations of iron, transferrin, haptoglobin, IgG, and $\operatorname{IgA}$ were measured at the Department of Clinical Chemistry, University Hospital, Uppsala. Erythrocyte sedimentaton rate according to Westergren was read after $1 \mathrm{~h}$. Serum ferritin was measured by a commercial radioimmunoassay and according to the manufacturer's instructions (Becton Dickinson Immunodiagnostics, NY). Lactoferrin was measured in plasma from blood anticoagulated with EDTA by a radioimmunoassay previously described. ${ }^{8}$

Student's $t$ test and linear regression analysis were used for statistical analysis.

\section{Results}

The iron stores in granulocytes and platelets isolated from patients with ankylosing spondylitis and healthy controls are presented in Fig. 1. The mean

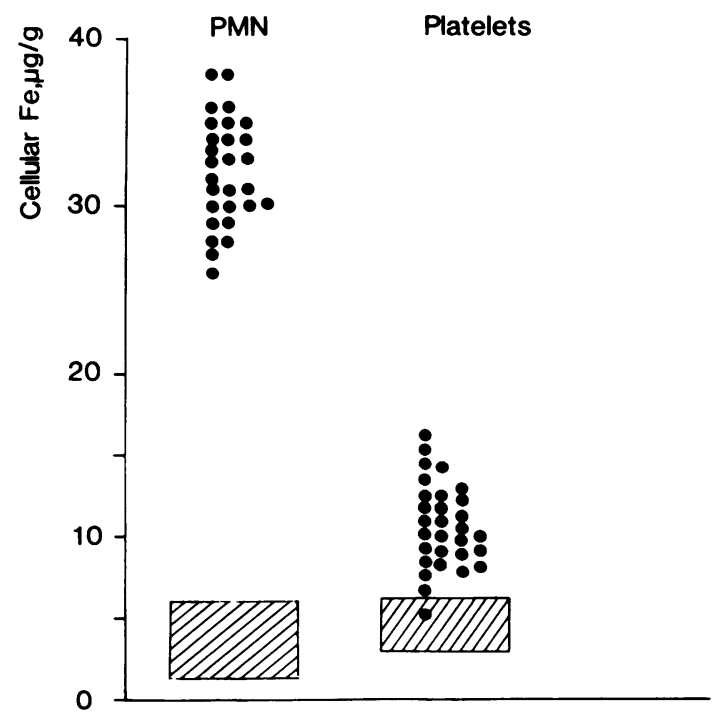

Fig. 1 The cellular stores of iron in PMNs and platelets isolated from patients with ankylosing spondylitis (filled circles). The striped areas represent the $2 S D$ ranges for iron in these cells isolated from healthy controls. 

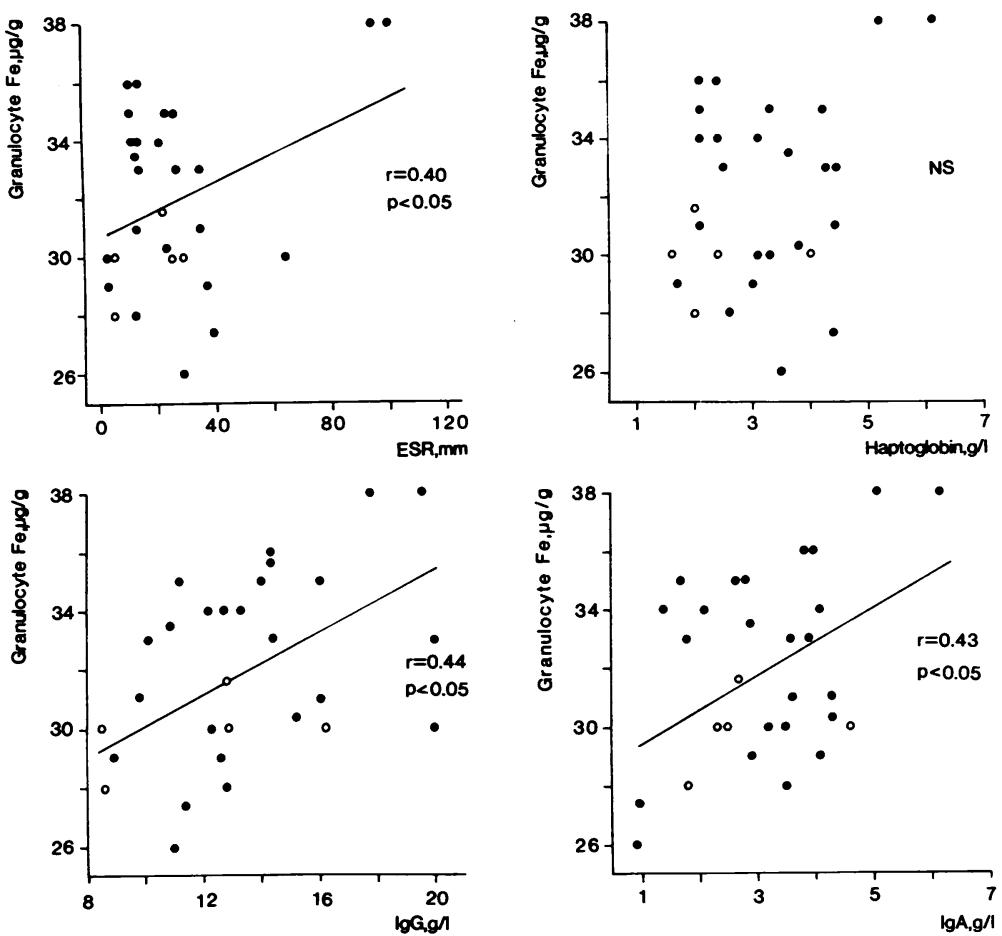

Fig. 2 Granulocyte iron v ESR, and serum levels of haptoglobin, $\operatorname{Ig} G$, and $\operatorname{Ig} A$ in male (O) and female $(\mathrm{O})$ patients with ankylosing spondylitis.
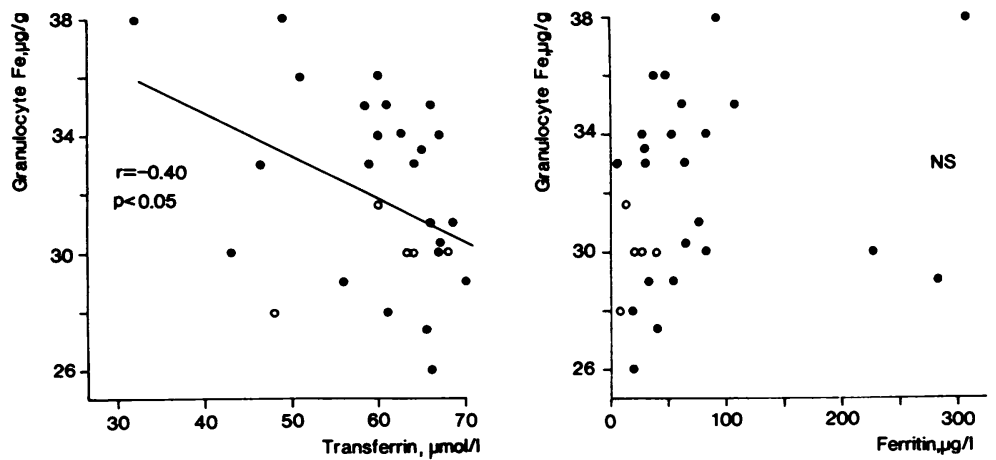

Fig. 3 Granulocyte iron $v$ serum level of transferrin, ferritin, lactoferrin, and iron in male (O) and female $(\mathrm{O})$ patients with
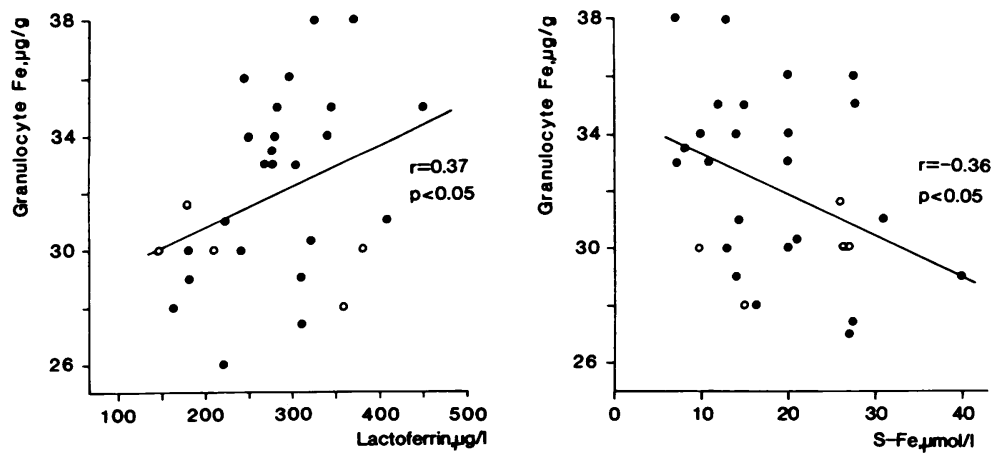
ankylosing spondylitis. 
(SD) iron content in patients' PMNs was 32 (3.1) $\mu \mathrm{g} / \mathrm{g}$ dry weight and in platelets $11(2.6) \mu \mathrm{g} / \mathrm{g}$ dry weight. Corresponding values for healthy controls were in PMNs $5.2(1.9) \mu \mathrm{g} / \mathrm{g}$ and in platelets 4.6 $(0.8) \mu \mathrm{g} / \mathrm{g}(\mathrm{p}<0.001)$. No sex or age dependency was found in patients or controls.

The inflammatory activity of the patients was defined by ESR, and serum levels of haptoglobin, IgG, and IgA. PMN iron was significantly correlated with the immunoglobulin levels and tended to correlate with the inflammatory activity defined by ESR and haptoglobin (Fig. 2). Platelet iron did not correlate with these variables reflecting disease activity (data not shown). Weak but significant relationships $(p<0.05)$ were observed between PMN iron stores and plasma lactoferrin, transferrin, and total serum iron but not with serum ferritin (Fig. 3). Platelet iron correlated with transferrin $(r=-0.47, p<0.01)$ but not with the other iron binding proteins analysed. Only three of the patients suffered from anaemia, defined as subnormal $\mathrm{Hb}$ values. The $\mathrm{Hb}$ values were significantly correlated with transferrin $(p<0.001)$ and serum $\mathrm{Fe}(\mathrm{p}<0.001)$ but not with serum ferritin and plasma lactoferrin. No relation was found between the $\mathrm{Hb}$ values and the cellular stores of iron (data not shown).

\section{Discussion}

This study has shown abnormal accumulation of iron in granulocytes and platelets from patients with ankylosing spondylitis. The same phenomenon has also been observed in a preliminary study on patients with rheumatoid arthritis and other connective tissue diseases. ${ }^{9}$ These observations extend the list of evidence for altered iron metabolism in chronic inflammation. The hypoferraemia of inflammatory disease has been attributed to a redistribution of iron mainly to RE cells of liver, spleen, and lymph nodes but also to synovial cells. ${ }^{10-13}$ This iron is stored intracellularly as ferritin but also as other cytoplasmatic, non-ferritin structures (haemosiderin, Perls' positive iron). ${ }^{2}$ Studies of synovial macrophages from patients with rheumatoid arthritis have shown large amounts of ferritin, possibly but not necessarily saturated with iron, but also the presence of Perls' positive iron. Synovial ferritin has been related to the inflammatory activity of the disease, which was not true for Perls' positive iron, which instead has been linked to the development of erosive joint damage. ${ }^{2}$ Ferritin iron was not measurable in granulocytes isolated from inflamed synovial fluid. ${ }^{14}$

Previous studies of the altered iron kinetics in inflammatory disease have suggested different mechanisms behind this phenomenon. Interleukin-1 which induces fever, leucocytosis, and an alteration in acute phase protein synthesis also induces hypoferraemia. ${ }^{15}$ This can be due to an increased iron uptake in certain cells and to a shift to a slower recirculating pathway within the cells. ${ }^{18}$ Similar inflammatory mechanisms may also underlie the accumulation of iron in granulocytes and platelets since a relation was found between the cellular iron stores and the laboratory signs of inflammatory activity defined by ESR and serum immunoglobulins $A$ and $G$. An altered iron uptake via the intestine could also influence the iron kinetics. ${ }^{16} 17$

In an attempt to elucidate further the altered iron kinetics and to discover from where the accumulated iron is derived the iron binding proteins in serum were measured. Serum ferritin is considered to reflect the total iron stores and this is true for the anaemia of iron deficiency. An increase of serum ferritin, however, may also be part of an acute phase reaction and therefore ferritin poorly reflects the total iron stores in chronic inflammation. ${ }^{18}$ Thus it is not surprising that we cannot find any correlation between serum ferritin and the cellular iron stores. The difficulty involved in clarifying the altered iron distribution was also illustrated by the negative correlation between serum transferrin and cellulae iron stores. This might merely reflect the fact that transferrin acts as a negative acute phase reactarf and does not at this point provide any simple solution. A role for lactoferrin in the altered iron metabolism has also been suggested. ${ }^{19}$ Lactoferrin is secreted from PMNs and appears in plasma in higher concentrations during inflammation. Lactoferrin can remove iron from its normal carrier protein transferrin and this iron-lactoferrin complex is then, by means of specific receptors, taken up by RE cells. ${ }^{20} 21$ Thus a cellular accumulation of iron can be achieved. Our observation that patients with ankylosing spondylitis have significantly higher plasma levels of lactoferrin than controls and that the lactoferrin values correlate with the acute phase reaction suggests an activated granulocyte mass in the disease. The observation that circulating lactoferrin correlates with the iron stores in granulocytes may suggest that mechanisms similar to those described in macrophages for the uptake of lactoferrin-iron complexes are also relevant for granulocytes. Iron binding proteins in PMNs other than lactoferrin and ferritin have been suggested but not identified. ${ }^{22}$ Granular proteins in platelets are also likely to take part in the iron storage and transport of iron.

The biological significance of the changes in iron distribution in inflammatory states could be manifold. A high cellular iron content is beneficial to the organism in certain situations and hazardous in 
others. Iron enhances the free radical production necessary to defeat invading bacteria, but excess of free iron promotes bacterial growth and must be prevented. ${ }^{23}$ Intracellular iron, which is not properly bound within ferritin, can in the rheumatic joint induce synthesis and release of collagenase and prostaglandins or promote the formation of toxic free radicals. ${ }^{24}$ Patients with $\beta$-thalassaemia, heavily iron overloaded from repeated transfusions, have neutrophils that show enhanced oxidative metabolism and increased superoxide production. ${ }^{25}$ Further evidence for the noxious effects of iron in rheumatic disease is given in the study by Blake and coworkers where intravenous iron dextran treatment is shown to promote synovitis concomitant with increased lipid peroxidation. ${ }^{26}$ Thus an initially appropriate inflammatory reaction can in the presence of excess iron be turned into a harmful and self perpetuating process. This study has shown that yet two other cell types, the PMNs and the platelets, have altered iron stores in inflammatory disease. This supports previous ideas of a crucial role for iron in these states. In order to elucidate the cellular structures that govern the storage and release of iron in inflammation further studies of subcellular organelles are needed.

This work was supported by grants from the Swedish Medical Research Council, the Swedish Natural Science Research Council, and Pharmacia, Sweden.

\section{References}

1 Hershko C, Cook J D, Finch C A. The effect of inflammation on iron exchange in the rat. Br J Haematol 1974; 28 : 67-75.

2 Blake D R, Gallagher P J, Potter A R, Bell M J, Bacon P A. The effect of synovial iron on the progression of rheumatoid disease. Arthritis Rheum 1984; 27: 495-501.

3 Blake D R, Bacon P A, Hall N D, Dieppe P A. Halliwell B, Gutteridge J M C. The importance of iron in rheumatoid disease. Lancet 1981; ii: $1142-4$.

4 Johansson E, Lindh U, Landström E. The incorporation of selenium and alterations of macro- and trace element levels in individual blood cells following supplementation with sodium selenite and vitamin E: a nuclear microprobe application. Biol Trace Elem Res 1983; 5: 433-47.

5 Lindh U. Elemental characterization of individual glia and glioma cells in the nuclear microprobe. Nucl Instr Methods 1982; 193: 343-7.

6 Lindh U. Elemental mapping of tissue sections by means of microparticle-induced X-ray emission spectroscopy and computer graphics. Anal Chim Acta 1983; 150: 233-44.
7 Uemura Y J, Kuno Y, Koyama H, Yamazaki T, Kienle P. A new way of determining concentrations in PIXE trace element analysis. Nucl Instr Methods 1978; 153: 573-9.

8 Venge P, Hällgren R, Stålenheim G, Olsson I. Effects of serum and cations on the selective release of granular proteins from human neutrophils during phagocytosis. Scand J Haematol 1979; 22: 317-26.

9 Svensson K, Hällgren R, Johansson E, Lindh U. Reduced zinc in peripheral blood cells from patients with inflammatory connective tissue diseases. Inflammation 1985; 9: 189-99.

10 Woyes W D, Bothwell T H, Finch C A. The role of the reticuloendothelial cell in iron metabolism. Br J Haematol 1960; 6: 43-55.

11 Muirden K D. Lymph node iron in rheumatoid arthritis. Ann Rheum Dis 1970; 29: 81-8.

12 Muirden K D. The anemia of rheumatoid arthritis. Aust Ann Med 1970; 19: 97-104.

13 Birgegård G, Caro J. Increased ferritin synthesis and iron uptake in inflammatory mouse macrophages. Scand J Haematol 1984; 33: 43-8.

14 Muirden K D. Ferritin in synovial cells in patients with rheumatoid arthritis. Ann Rheum Dis 1966; 25: 387-401.

15 Pekarek R S, Wannemacher R W, Beisel. The effect of leukocyte endogenous mediator on the tissue distribution of zinc and iron. Proc Soc Exp Biol Med 1972; 140: 685-8.

16 Fillet $G$, Cook J D, Finch C A. A biological model for reticuloendothelial iron transport. J Clin Invest 1974; 53: 1527-33.

17 Raymond F D, Bowie M A, Dugan A. Iron metabolism in rheumatoid arthritis. Arthritis Rheum 1965; 8: 233-43.

18 Birgegård $G$, Hällgren $R$, Killander $A$, Strömberg $A$, Venge $P$, Wide $L$. Serum ferritin during infection. A longitudinal study. Scand J Haematol 1978; 21: 333-40.

19 Birgens H S. The biological significance of lactoferrin in haematology. Scand J Haematol 1984; 33: 225-30.

20 Aisen $\mathrm{P}$, Brown $\mathrm{E} \mathrm{B}$. The iron-binding function at transferrin in iron metabolism. Semin Hematol 1977; 14: 31-53.

21 Van Snick J L, Masson P L, Heremans J F. The involvement of lactoferrin in the hyposideremia of acute inflammation. $J$ Exp Med 1974; 140: 1068-84.

22 Parmley R T, Takagi M, Barton J C, Boxer L A, Austin R L. Ultrastructural localization of lactoferrin and iron-binding protein in human neutrophils and rabbit heterophils. Am J Pathol 1982; 109: 343-58.

23 Bullen J J. The significance of iron in infection. Rev Infect Dis 1981; 3: 1127-38.

24 Gutteridge J M C, Rowley D A, Halliwell B. Superoxidedependent formation of hydroxyl radicals in the presence of iron salts. Detection of free iron in biological systems by the bleomycin-dependent degradation of DNA. Biochem J 1981; 199: 263-5.

25 de Martino M, Rossi M E, Resti M, Vullo C, Vierucci A. Changes in superoxide anion production in neutrophils from multi transfused $\beta$-thallasemia patients: correlation with ferritin levels and liver damages. Acta Haematol (Basel) 1984; 71: 289-98.

26 Blake D R, Lunec J, Ahern M, Ring E F J, Bradfield J, Gutteridge J M C. Effect of intravenous iron dextran on rheumatoid synovitis. Ann Rheum Dis 1985; 44: 183-8. 